\title{
Senso democrático e Censo demográfico: uma questão de consciência e liberdade
}

\section{Democratic sense and demographic census: a matter of awareness and freedom}

\section{Sentido democrático y censo demográfico: una cuestión de conciencia y libertad}

Autor ${ }^{1}$ https://orcid.org/0000-0002-1597-5180

\footnotetext{
1 Universidade Estadual de Minas Gerais/Universiade Federal de Minas Gerais, Belo Horizonte, Minas Gerais, Brasil, dca.uemg@gmail.com
}

Recebido em: $\underline{30 / 11 / 2021}$

Aceito para publicação em: 30/12/2021

\begin{abstract}
Resumo
Este artigo é uma revisão de literatura que traz à baila, nos campos geopolítico e filosófico, a polêmica em torno da decisão do Estado brasileiro em cancelar a realização do Censo demográfico justificado na falta de recursos financeiros demandados para a execução dessa pesquisa secular, de cárater nacional e que trata da realidade demográfica do país. A partir da querela jurídico-estatal, desenvolve-se um referencial teórico com a perspectiva de associar o Censo, instrumento de gestão e divulgação da informação social, econômica, cultural e demográfica da sociedade brasileira indispensável, à construção de uma consciência social livre preconizada por um Estado democrático. Conclui-se entendendo que negligenciar a importância do Censo demográfico significa impossibilitar, de certo modo, o Senso democrático.
\end{abstract}

Palavras-chave: Censo demográfico. Senso democrático. Consciência livre.

\begin{abstract}
This article is a literature review that brings to light, in the geopolitical and philosophical fields, the controversy surrounding the decision of the Brazilian State to cancel the realization of the Demographic Census justified by the lack of financial resources required for the execution of this secular research, of character national and that deals with the demographic reality of the country. From the legal-state quarrel, a theoretical framework is developed with the perspective of associating the Census, an instrument for the management and dissemination of social, economic, cultural and demographic information of Brazilian society, which is indispensable, to the construction of a free social conscience advocated by a democratic state. It concludes by understanding that neglecting the importance of the Demographic Census means, in a certain way, making the democratic Sense impossible.
\end{abstract}

Keywords: Demographic census. Democratic sense. Free consciousness. 


\section{Resumen}

Este artículo es una revisión de la literatura que saca a la luz, en los campos geopolítico y filosófico, la controversia en torno a la decisión del Estado brasileño de cancelar la realización del Censo Demográfico justificada por la falta de recursos financieros necesarios para la ejecución de esta investigación secular., de carácter nacional y que se ocupa de la realidad demográfica del país. Desde la disputa legal-estatal, se desarrolla un marco teórico con la perspectiva de asociar el Censo, instrumento de gestión y difusión de la información social, económica, cultural y demográfica de la sociedad brasileña, indispensable, a la construcción de un libre conciencia social defendida por un estado democrático. Concluye entendiendo que descuidar la importancia del Censo Demográfico significa, en cierto modo, imposibilitar el Sentido democrático.

Palabras clave: Censo demográfico. Sentido democrático. Conciencia libre.

"Quanto mais vocêé informado do inessencial, menos você sabe sobre si mesmo e mais vocêé controlado pela lógica do medo" (SODRÉ, 1981).

\section{Introdução}

A atual cena social da política brasileira tem sido marcada por controvérsias envolvendo princípios basilares para qualquer nação constituída sob a égide da Democracia. Tal afirmação deve-se ao fato de que, até o momento da escrita deste artigo, cinco grandes contendas envolveram os pilares da nação brasileira, resultando, não apenas em manchetes nos noticiários nacionais e internacionais, mas em processos dirimidos no âmbito da mais alta Corte dos litígios judiciais do país: o Supremo Tribunal Federal (STF).

O primeiro deles referiu-se aos atos antidemocráticos promovidos por apoiadores do atual chefe do poder executivo federal do Brasil, culminando como pauta processual no STF com a investigação, tanto de civis comuns, quanto de próprios governantes, como se destaca em parte da decisão do ministro Alexandre de Moraes na qual determinou "a imediata efetivação da prisão em flagrante delito, por crime inafiançável do deputado federal Daniel Silveira" (BRASIL, p. 7, 2021):

Na data de hoje (16/02), chegou ao conhecimento desta CORTE vídeo publicado pelo Deputado Federal Daniel Silveira, disponibilizado através do link: https://youtu.be/jMfInDBItog, no canal do youtube denominado "Política Play", em que o referido deputado durante $19 \mathrm{~m} 9 \mathrm{~s}$, além de atacar frontalmente os Ministros do Supremo 
ALVES, D. C.

Tribunal Federal, por meio de diversas ameaças e ofensas à honra, expressamente propaga a adoção de medidas antidemocráticas contra o Supremo Tribunal Federal, defendendo o AI-5; inclusive com a substituição imediata de todos os Ministros, bem como instigando a adoção de medidas violentas contra a vida e segurança dos mesmos, em clara afronta aos princípios democráticos, republicanos e da separação de poderes (BRASIL, 2021, p. 1).

Em meio a ataques aos sustentáculos de um país democrático de direito, outro pilar que passou a ser alvo de discursos ofensivos proferidos pelo chefe da nação brasileira e pelo ministro da pasta respectiva à época, foi a Educação, ensejando, mais uma vez, a interferência judicial, como se extrai:

Pelo que consta da inicial, em entrevista concedida ao "Jornal da Cidade", o interpelado, na condição de Ministro da Educação, fez uma série de inferências sobre atividades ilícitas nas universidades federais, das quais pode-se, segundo os requerentes, constatar a prática de crimes contra a honra dos docentes, servidores e alunos integrantes destas universidades (BRASIL, 2020, p. 1).

A terceira contenda, e não menos grave, referiu-se aos supostos crimes ambientais provocados pelo próprio ministro do meio ambiente, o que resultou em processos investigativos sobre prováveis crimes cometidos por aquele que deveria ser o guardião máximo do meio ambiente no Brasil. Para tanto, destaca-se uma das últimas acusações:

[...] delegado de Polícia Federal Alexandre Silva Saraiva em desfavor do Ministro do Meio Ambiente Ricardo de Aquino Sales, do Senador Telmário Mota e do Presidente do IBAMA Eduardo Binresta [...] concluiu que [...] resta patente que o Ministro RICARDO DE AQUINOS SALLES, o SENADOR TELMÁRIO MOTA o Presidente do IBAMA EDUARDO BIM, de forma consciente e voluntária, e em unidade de desígnios, dificultam a ação fiscalizadora do Poder Público no trato de questões ambientais, assim como patrocinam, direta, interesses privados (de madeireiros) e ilegítimos perante a administração pública, valendo-se de suas qualidades de funcionários públicos [...] Pelo exposto, defiro o pedido da Procuradoria-Geral da República e determino a instauração de inquérito em desfavor do Ministro do Meio Ambiente Ricardo de Aquino Sales pelos fatos 
ALVES, D. C.

descritos no pleito do Ministério Público, com o objetivo de apurar prática dos crimes tipificados no art. 321 do Código Penal (advocacia administrativa), no art. 69 da Lei 9.605/1998 (obstar ou dificultar a fiscalização ambiental) e no art. $2^{\circ}$, § $1^{\circ}$, da Lei 12.850/2013 (impedir ou embaraçar a investigação de infração penal que envolva organização criminosa) (BRASIL, 2021, p. 2-8).

E, por último, a contenda diretamente relacionada à motivação deste artigo, a saber: necessidade de imposição judicial para que o país realize o Censo demográfico no ano de 2022:

O direito à informação é basilar para o Poder Público formular e implementar políticas públicas. Por meio de dados e estudos, governantes podem analisar a realidade do País. A extensão do território e o pluralismo, consideradas as diversidades regionais, impõem medidas específicas. O Censo, realizado historicamente pelo Instituto Brasileiro de Geografia e Estatística - IBGE, permite mapear as condições socioeconômicas de cada parte do Brasil. E, então, o Executivo e o Legislativo elaboram, no âmbito do ente federado, políticas públicas visando implementar direitos fundamentais previstos na Constituição Federal. Como combater desigualdades, instituir programas de transferência de renda, construir escolas e hospitais sem prévio conhecimento das necessidades locais? (BRASIL, 2021, p. 3).

Continua o ministro Marco Aurélio na sustentação da sua decisão:

A União e o IBGE, ao deixarem de realizar o estudo no corrente ano, em razão de corte de verbas, descumpriram o dever específico de organizar e manter os serviços oficiais de estatística e geografia de alcance nacional - artigo 21, inciso XV, da Constituição de 1988. Ameaçam, alfim, a própria força normativa da Lei Maior. Surge imprescindível atuação conjunta dos três Poderes, tirando os compromissos constitucionais do papel. No caso, cabe ao Supremo, presentes o acesso ao Judiciário, a aplicabilidade imediata dos direitos fundamentais e a omissão dos réus, impor a adoção de providências a viabilizarem a pesquisa demográfica. 3. Defiro a liminar, para determinar a adoção de medidas voltadas à realização do Censo, observados os parâmetros preconizados pelo IBGE, no âmbito da própria discricionariedade técnica (BRASIL, 2021, p. 4). 
O Censo é uma política pública implementada no Brasil desde o ano de 1872 e, em 1991, por força da Lei n⿳o 8.184/1991, o Censo demográfico deixou de ser um ato discricionário, ou seja, não se trata mais de um capricho do Estado em querer ou não fazer, é uma obrigação legal, dado o fato de se constituir como o instrumento que permite o governo planejar políticas públicas adequadas para uma realidade conhecida.

Art. $1^{\circ}$ A periodicidade dos Censos Demográficos e dos Censos Econômicos, realizados pela Fundação Instituto Brasileiro de Geografia e Estatística (IBGE), será fixada por ato do Poder Executivo, não podendo exceder a dez anos a dos Censos Demográficos e a cinco anos a dos Censos Econômicos. Art. $2^{\circ} \mathrm{A}$ Fundação Instituto Brasileiro de Geografia e Estatística (IBGE) realizará, tendo como referência, o ano de 1991, os seguintes Censos: a) Censo Demográfico (população e domicílios); b) Censo Econômico (agropecuário, industrial, comercial e de serviços) (BRASIL, 1991).

O desconhecimento da realidade dificulta a assertividade da ação política, impossibilita a sociedade aferir a qualidade da atuação do poder público, prejudica pesquisas científicas e não permite aos brasileiros e ao mundo conhecer a realidade do país. Nesse sentido, não pode o poder público, com justificativas de racionalidade econômica, tergiversar da sua obrigação legal em traçar o diagnóstico decenal do país, a fim de colocar em prática políticas públicas efetivas, isto é, situadas à realidade concreta da nação brasileira.

Em meio a essas contendas, o país e o mundo vivem uma crise híbrida, incialmente sanitária, mas que invadiu todas as outras dimensões da vida social, especialmente a política e a economia, fazendo-se necessária a instalação de uma Comissão Parlamentar de Inquérito (CPI) que, conforme o parágrafo $3^{\text {o }}$ do artigo 58 da Constituição, regulamentado pela Lei 1.579, de 1952, teve como finalidade garantir que o Parlamento exercesse o seu papel de fiscalizador do Estado.

Essa CPI, determinada pela Suprema Corte, atribuiu ao Senado apurar supostas ações e omissões do governo federal no combate à pandemia, dado o 
catastrófico cômputo de mais de meio milhão de mortes à época desta produção textual. O STF, nos termos abaixo, determinou a instalação da CPI da pandemia no Senado:

verifico, nesta primeira análise, a plausibilidade jurídica dos fundamentos da impetração. De acordo com consistente linha de precedentes do STF, a instauração do inquérito parlamentar depende, unicamente, do preenchimento dos três requisitos previstos no art. 58, § 3ํ, da Constituição. São eles: (i) o requerimento de um terço dos membros das casas legislativas; (ii) a indicação de fato determinado a ser apurado; e (iii) a definição de prazo certo para sua duração. Significa dizer que a instalação de uma CPI não se submete a um juízo discricionário do presidente ou do plenário da casa legislativa. Não pode o órgão diretivo ou a maioria parlamentar se opor a tal requerimento por questões de conveniência e oportunidade políticas. Atendidas as exigências constitucionais, impõe-se a criação da Comissão Parlamentar de Inquérito (BRASIL, 2021, p. 9).

Vê-se, portanto, um governo executivo federal em constante litígio com preceitos constitucionais basilares, dentre os quais, os próprios princípios democráticos de um país de direito, os quais foram essenciais, inclusive, para a sua ascensão ao poder, sobretudo, num contexto marcado pela predominância da cultura digital nas relações sociais, em que o acesso à informação por meio das mais diversas mídias sociais movimentou o cenário das eleições do ano de 2018.

Foi pelo direito irrestrito ao acesso à informação, tendo como primado maior o direito constitucional da liberdade de expressão, que a transparência e a disseminação dos discursos e das propostas de novos atores políticos ganharam, por fibras opticas, os quatro cantos do país. Adverte-se, no entanto, que a ampliação desse direito, em um contexto digital de uso das técnias e seus artefatos sob a falsa ideia do anonimato, extrapola-se, tanto que, no mencionado cenário das eleições presidenciais no Brasil, o resultado foi a instalação da Comissão Parlamentar Mista de Inquérito (CPMI) das Fake News provocada pelo Requerimento de Instituição de CPMI nำ11/2019: 
ALVES, D. C.

o desenvolvimento desse ambiente fértil e hostil para a disseminação opiniões viabilizou, ainda, a automatização de ferramentas de publicação, resultando no surgimento e na propagação de robôs contas controladas por softwares que se fazem passar por seres humanos, os quais já dominam parte das redes sociais e participam ativamente das discussões em momentos políticos de grande repercussão. Nas discussões políticas, os robôs têm sido usados por todo o espectro partidário não apenas para conquistar seguidores, mas também para conduzir ataques a opositores e forjar discussões artificiais. Manipulam debates, criam e disseminam notícias falsas - as chamadas fake News -, e influenciam a opinião pública por meio da postagem e replicação de mensagens em larga escala. [...]Ante o exposto, torna-se indispensável a instalação imediata de uma Comissão Parlamentar Mista de Inquérito. Dada a complexidade dos fatos, novos indícios poderão ser adicionados ao processo na medida em que a Comissão desenvolva seus trabalhos (BRASIL, 2019, p. 2-8).

Controversamente, o atual governo executivo federal, eleito com base em preceitos democráticos, especialmente o direito à informação, hoje, ignora a importância do conhecimento público da real situação de um país continental e repleto de desigualdades, como é o Brasil, quando se abstém do dever legal de realizar o Censo.

Se abster dessa obrigação é, tanto um descumprimento da lei, quanto retirar da população o direito de saber da realidade do seu país, de fiscalizar a atuação do poder público e de saber de si enquanto nação.

Ante o exposto, este artigo tem como principal questão: pode um Brasil do século XXI, com alto grau de capacidade técnica, quando comparado ao Brasil do século XIX que já realizava o Censo, sem números, sem radiografia da sua realidade?

Com o intento de encontrar respostas para esse questionamento central, o objetivo geral é evidenciar a importância do Censo demográfico como direito constitucional garantidor do acesso da informação à população, pelo que, se constitui como um instrumento geopolítico, especialmente, no que diz respeito à defesa por um Estado, efetivamente, democrático, dado que, quando se considera apenas uma de suas facetas - a jurídica -, o Censo potencializa o direito da sociedade em fiscalizar e verificar o atendimento do poder público à Carta Magna do país. 
Para tanto, realiza-se uma revisão de literatura sobre um termo amplamente conhecido, porém, esvaziado de sentido na cena social da política brasileira, a saber: Democracia. A esse termo vincula-se a finalidade do Censo demográfico que, como se apresenta, atualmente é negligenciado por uma geopolítica brasileira avessa à transparência da informação demográfica e econômica como direito constitucional basilar para uma nação que se diz democrática.

Conclui-se o artigo tecendo algumas considerações acerca de uma geopolítica brasileira que opera, na atualidade, com discursos tergiversantes da efetividade da atuação do poder público em relação a pautas que levantou como lemas de sua campanha política, dentre as quais, o crescimento econômico do país, tendo em vista que, negar o Censo torna esse lema mero discurso retórico de campanha, pois, não há como medir e/ou avaliar o crescimento econômico de um país sem saber, em números situados, a sua realidade socioeconômica.

\section{Democracia, Liberdade e Censo}

Em um contexto marcado por debates em torno da crise da Democracia, há que se discutir sobre as (im)possibilidades desse regime político em países que, a exemplo do Brasil, valores democráticos fundamentais, como a Liberdade, não raras vezes, têm sido avocados como negação do próprio Estado democrático de direito.

Para tanto, parte-se da premissa de que a Democracia

antes de ser forma política, é forma de vida, se caracteriza sobretudo por forte dose de transitividade de consciência no comportamento do homem. Transitividade que não nasce e nem se desenvolve a não ser dentro de certas condições em que o homem seja lançado ao debate, ao exame de seus problemas e dos problemas comuns. Em que o homem participe (FREIRE, 1967, p. 81).

À luz do filósofo e educador brasileiro Paulo Freire (1921 - 1997), o mencionado valor é fundamental para que a Democracia se realize pela participação, o que explica a recorrência histórica dos debates conceituais em torno da Democracia 
e da Liberdade, cuja materialidade "vai depender das opções concretas que os homens realizem" (FREIRE, 1967, p. 16).

Há quem entenda a Liberdade como direito irrestrito de expressão, porém, há quem concebe a Liberdade como o direito à dignidade humana, o que inclui ter educação, saúde, emprego e moradia e, por isso, a entende como superior à concepção anterior; e, também, há quem define a Liberdade como uma mera fantasia, tendo em vista que todos são social e psicologicamente condicionados. Essas diferentes concepções levam a humanidade, nos diferentes tempos e espaços, a se questionar sobre o que é ser livre e sobre quais são os obstáculos para a Liberdade.

Todavia, tendo a Liberdade esse papel fundamental para romper com os véus da ignorância, porque o sujeito aceita dela abrir mão?

Sobre esse questionamento, La Boétie (1976) permite pensar que ser livre implica em assumir responsabilidades e escolhas e a humanidade está acostumada com a condição de ser objeto, não sabe ser sujeito. Ela é constantemente seduzida pela servidão. Há um desejo confortável pela submissão. Por tudo isso, na atual era da Liberdade, não tê-la é uma dócil e retórica maneira de reivindicá-la, pois no fundo, abre-se mão dela pelo gosto do homem-objeto em contraposição ao temor pela responsabilidade que se é obrigado quando na condição de homem-sujeito.

Assim, como defendia Adorno (1995), a supressão da Liberdade se materializa em consciências não emancipadas, o que contrasta com qualquer perspectiva de vida democrática e livre, visto que,

a exigência de emancipação parece ser evidente numa democracia [...] A democracia repousa na formação da vontade de cada um em particular, tal como ela se sintetiza na instituição das eleições representativas. Para evitar um resultado irracional é preciso pressupor a aptidão e a coragem de cada um em se servir de seu próprio entendimento (ADORNO, 1995, p.169).

Adorno (1995), apropriando-se da expressão kantiana, defendia a ideia de consciência emancipada como sinônimo de Aufklärung, que se traduz em 
esclarecimento, ou seja, na possibilidade que permite o homem ser livre. Nas palavras de Kant (1985):

\begin{abstract}
esclarecimento é a saída do homem da menoridade pela qual é o próprio culpado.Menoridade é a incapacidade de servir-se do próprio entendimento sem direção alheia. O homem é o próprio culpado por esta incapacidade, quando sua causa reside na falta, não de entendimento, mas de resolução e coragem de fazer uso dele sem a direção de outra pessoa. Sapereaude! Ousa fazer uso de teu próprio entendimento! (KANT, 1985, p. 407).
\end{abstract}

Para correntes filosóficas existencialistas ancoradas no pensamento de Jean Paul Sartre (1905-1980), toda a realidade humana é livre

porque está perpetuamente desprendida de si mesmo, e porque aquilo que foi está separado por um nada daquilo que é e daquilo que será. E, por fim, porque seu próprio ser presente é nadificação na forma do 'reflexorefletidor'. O homem é livre porque não é si mesmo, mas presença a si. O ser que é o que é não poderia ser livre. A liberdade é precisamente o nada que tendo sido no âmago do homem e obriga a realidade humana a fazer-se em vez de ser (SARTRE, 1998, p. 545).

Mas essa Liberdade, para Sartre (1998), é provocadora de angústia, cuja qualquer tentativa de fuga "não passa de uma forma de tomar consciência da própria angústia" (SARTRE, 1998, p.89), pelo que, a falta da Liberdade passa estar associada a fatores externos, isto é, a um subterfúgio da consciência em relação à angústia que a aflige. A esses fatores externos, o filósofo chamou de má fé, pois

tendo definido a situação do homem como uma escolha livre, sem desculpas e sem auxílio, consideramos que todo homem que se refugia por trás da desculpa de suas paixões, todo homem que inventa um determinismo, é um homem de má fé. É possível objetar o seguinte: por que razão ele não poderia escolher-se como um homem de má fé? E eu respondo que não tenho que julgá-lo moralmente, mas defino a sua má fé como um erro. Não podemos escapar, aqui, a um juízo de verdade. A má fé é, evidentemente, uma mentira, pois dissimula a total liberdade do engajamento. No mesmo 
ALVES, D. C.

plano, direi que tem má fé, igualmente, aquele que declara que certos valores preexistem a si próprios; estarei em contradição comigo mesmo se, concomitantemente, quiser esses valores e afirmar que eles me são impostos. Alguém pode perguntar-me: e se eu quiser ser um homem de má fé? Eu responderei: não há motivo algum para que você não possa sê-lo, mas declaro que você tem má fé e que a atitude de estrita coerência é a atitude de boa-fé. Além disso, posso fazer um juízo moral. Quando declaro que a liberdade, através de cada circunstância concreta, não pode ter outro objetivo senão o de quererse a si própria, quero dizer que, se alguma vez o homem reconhecer que está estabelecendo valores, em seu desamparo, ele não poderá mais desejar outra coisa a não ser a liberdade como fundamento de todos os valores. Isso não significa que ele a deseja abstratamente. Mas, simplesmente, que os atos dos homens de boa fé possuem como derradeiro significado a procura da liberdade enquanto tal (SARTRE, 1970, p. 18-19).

O certo é que, independente da corrente filosófica, se existencialista, marxista ou outra, o conceito de Liberdade ocupa o eixo central na discussão sobre a própria definição de ser humano.

A organicidade que carrega a Liberdade é verificada em diferentes épocas e grupos, nos mais variados contextos espaço-temporais, que lhe deram vestimentas semânticas diversas. Mas, em pleno século XXI, a questão persiste: afinal, o que vem a ser a Liberdade num Estado democrático de direito?

E no atual contexto brasileiro, marcado pela polarização da cena política, postura que, conforme já criticava o filósofo francês humanista La Boétie (1976), mitiga o debate, pois impede a percepção de outras gradações de cores que não apenas a admitida pelo polarizador, o qual inverte o pensar pelo mero adjetivar, os valores democráticos têm, a todo o momento, sido pautas do judiciário, o que torna mais do que necessário pensar sobre a relação Liberdade e Democracia para antes e além da retórica preambular da Carta Magna que a define como valor supremo para a construção de uma sociedade fraterna, pluralista e sem preconceitos, fundada na harmonia social e comprometida, na ordem interna e internacional, com a solução pacífica das controvérsias (BRASIL, 1988). 
A esse ser polarizador, Freire (1967) chama de sectário em oposição ao radical, por entender que este "rejeita o ativismo e submete sempre sua ação à reflexão. $\mathrm{O}$ sectário seja de direita ou de esquerda, se põe diante da história como o seu único fazedor. Como seu proprietário" (FREIRE, 1967, p. 50).

Prossegue o autor em seu raciocínio acerca das distinções entre o sujeito sectário e o radical:

diferem porque, enquanto um pretende detê-la, o outro antecipála. Se a história é obra sua, se lhe pertence, pode um detê-la quando quiser, o outro antecipá-la, se lhe aprouver. Daí se identificarem na imposição de suas convicções. Na redução do povo à massa. O povo não conta nem pesa para o sectário, a não ser como suporte para seus fins. Deve comparecer ao processo ativistamente. Será um comandado pela propaganda intoxicadora de que não se adverte. Não pensa. Pensam por ele e é na condição de protegido, de menor de idade, que é visto pelo sectário, que jamais fará uma revolução verdadeiramente libertadora, precisamente porque também não é livre. Para o radical, que não pode ser um centrista ou um direitista, não se detém nem se antecipa a História, sem que se corra o risco de uma punição. Não é mero espectador do processo, mas cada vez mais sujeito, na medida em que, crítico, capta suas contradições. Não é também seu proprietário. Reconhece, porém, que, se não pode deter nem antecipar, pode e deve, como sujeito, com outros sujeitos, ajudar e acelerar as transformações, na medida em que conhece para poder interferir (FREIRE, 1967, p. 50-51).

Um breve revisitar da história da Democracia no mundo permite apreender que ela surge, incialmente, como o regime político pautado na priorização da vontade da maioria em detrimento da minoria. Esse conflito de vontades excluía, de certa forma, sempre a outra parte, a menos numerosa, como assim problematizaram Hamilton, Madison e Jay (1985) no contexto da elaboração da constituição norteamericana em 1788:

quando em uma república se têm obtido os meios de defender a nação contra a tirania dos seus chefes, não estão ainda resolvidas todas as questões sociais; trata-se, além disto, de defender uma parte da sociedade contra a injustiça de outra parte mais numerosa. As 
diferentes classes de cidadãos têm necessariamente interesses diversos; e quando a maioria está unida por um interesse comum, acham-se necessariamente em perigo os direitos da minoria (HAMILTON; MADISON; JAY, 1985, p. 132).

Contra o problema da submissão da minoria pela maioria, Hamilton, Madison e Jay (1985) entendiam que, para a ele se antecipar, haveria apenas "dois modos: [...] o primeiro, criar na sociedade uma vontade independente da maioria e, portanto, da sociedade mesma; o segundo, fazer entrar na sociedade tantas classes diferentes de cidadãos quanto seja preciso, para que não possa ter lugar uma combinação injusta da maioria [...]" (HAMILTON; MADISON; JAY, 1985, p. 132).

$\mathrm{O}$ que esses pensadores estadistas queriam enfatizar, diante da maior experiência democrática que saltava aos seus olhos no final do século XVIII, era a preocupação do poder tirano exercido por uma maioria democrática sobre as outras partes minoritárias da sociedade. Dessa forma, as principais questões por eles colocadas eram: como garantir a diversidade numa unidade? Como garantir a Democracia num tecido social híbrido e múltiplo em todos os sentidos?

À vista dessas duas perguntas centrais, os federalistas instigaram a pensar a Democracia para além de um viés idealizado, pelo que, tanto as virtudes - limite do poder, isonomia cidadã, defesa da representação e racionalidade democrática -, quanto os riscos a elas, deveriam ser objeto de análise política sob pena destes anularem aquelas e, com isso, negarem a base da racionalidade política prática, que chamavam-na de mediação, isto é, o diálogo, sem o qual, a Democracia perde o seu cerne, já que se constitui como o princípio que afasta a fácil manipulação da passionalidade humana pelo poder demagógico imposto sob um falso crivo democrático.

A respeito da mencionada forma de poder, no cenário das últimas eleições presidenciais no Brasil, o poder demagógico, que encontrou nas tecnologias digitais da informação e comunicação (TDIC) um disseminador; ele foi central para dominar a passionalidade humana distanciando as pessoas da virtude da racionalidade 
democrática. Essa supremacia do poder demagógico, potencializado pelas TDIC, foi assim descrito por Eco (2015) quando do seu discurso durante uma premiação com o título de Doutor Honoris Causa em Comunicação e Cultura na Universidade de Turim:

as mídias sociais deram o direito à fala a legiões de imbecis que, anteriormente, falavam só no bar, depois de uma taça de vinho, sem causar dano à coletividade. Diziam imediatamente a eles para calar a boca, enquanto agora eles têm o mesmo direito à fala que um ganhador do Prêmio Nobel. O drama da internet é que ela promoveu o idiota da aldeia a portador da verdade (ECO, 2015).

O mundo digital, para Eco (2015), empobreceu o debate democrático dado que, ao mesmo tempo que ampliou o alcance das virtudes democráticas, especialmente a Liberdade de expressão, tendo o debate de opiniões como o principal propulsor, deu visibilidade a posturas e pensamentos que atentam contra o próprio direito democrático da Liberdade, resultando, assim, num paradoxo da Democracia contemporânea: a Liberdade seria, diante da democratização da opinião, problema ou o próprio fazer democrático? A Liberdade de expressão poderia, inclusive, negar a própria Democracia, da qual resulta como um direito inalienável? Como manter o sistema democrático ancorado na Liberdade de expressão, sem tolher essa Liberdade?

Em uma Democracia é prescrito que todos têm o direito de opinar, mas esse direito não credita o mesmo valor para as diferentes opiniões. Todavia, as TDIC tornaram tênue essa ideia da valoração dos discursos. E quando essa valoração é perdida, a própria Democracia corre perigo.

Um desses perigos foi o que se passou a chamar de política da identidade, em que a identidade, associada normalmente ao gênero, à religião e à etnia, passa a determinar a política e não mais necessariamente as virtudes democráticas. Estas, são colocadas em segundo plano, pelo que, o requerido e banalizado lugar de fala identitário passa a extrapolar o democrático em si, fechando-se, com isso, em política 
da identidade que, quando não derivada de um lugar comum, perde a sua natureza democrática, já que,

opera na suposição de que identidades essenciais entre as comunidades marginalizadas (por razões raciais, de gênero e sexuais) são as que merecem reconhecimento. Em geral, política de identidades não se compromete em nível de Estado e permanece na esfera da sociedade civil (MIGNOLO, 2008, p. 312).

Encontrar o ponto equidistante entre Liberdade e inversão da lógica da política da identidade para a identidade em política, uma vez que esta opera, segundo Mignolo (2008), em oposição àquela, desligando-se "da jaula de ferro dos 'partidos políticos' como tem sido estabelecido pela teoria política moderna/colonial e eurocentrada" (MIGNOLO, 2008, p. 312), na perspectiva de não negar as virtudes democráticas que se realizam no lugar comum de fala, é o que, na atualidade, parece despontar como desafio em um Brasil que se quer democrático, mas que, não raramente, excede ou falta em Liberdade, assim como, pratica uma política da identidade, quando se sabe que, sob o prisma da Democracia,

a identidade em política, em suma, é a única maneira de pensar descolonialmente (o que significa pensar politicamente em termos e projetos de descolonização). Todas as outras formas de pensar (ou seja, que interferem com a organização do conhecimento e da compreensão) e de agir politicamente, ou seja, formas que não são descoloniais, significam permanecer na razão imperial; ou seja, dentro da política imperial de identidades (MIGNOLO, 2008, p. 290).

Como quesito para a racionalidade prática da Democracia, o lugar comum de fala, entendido como o rompimento “com o silêncio instituído para quem foi subalternizado, um movimento no sentido de romper com a hierarquia, muito bem classificada por Derrida como violenta “(RIBEIRO, 2017, p. 90), pressupõe

ligar a descolonialidade com a identidade em política, a opção descolonial revela a identidade escondida sob a pretensão de teorias 
democráticas universais ao mesmo tempo que constrói identidades racializadas que foram erigidas pela hegemonia das categorias de pensamento, histórias e experiências do ocidente (mais uma vez, fundamentos gregos e latinos de razão moderna/ imperial) (MIGNOLO, 2008, p. 297).

Exercer a Liberdade de expressão em uma sociedade democrática perpassa, então, por uma postura ética. Ética porque "saber o lugar de onde falamos é fundamental para pensarmos as hierarquias, as questões de desigualdade, pobreza, racismo e sexismo" (RIBEIRO, 2017:84).

Cogitar a possibilidade de se debater a Liberdade como vício em uma sociedade democrática deve-se, portanto, ao esvaziamento e/ou não ressignificação do que venha a ser Democracia e, por sua vez, Ética numa sociedade, pois "embora a ética esteja na moda e todo mundo fale dela, ninguém chega realmente a acreditar que ela seja importante, e mesmo essencial para viver" (CORTINA, 2003, p. 18).

Por isso, nunca é demasiado discutir sobre Democracia na sociedade, ressalvando-se que falar em Democracia pressupõe compreender a sua eticidade, haja vista que, conforme o pensamento desconstrucionista do filósofo Jacques Derrida (1930 - 2004), só existe Ética em relação ao outro, portanto, adequada a um princípio de vida coletiva e democrática, cuja imposição prescritiva nega, inclusive, a própria Ética, devendo o foco estar no processo e não na proposição do conteúdo de uma Ética.

Por Democracia, é razoável o entendimento de que ela não é vontade da maioria, pois o desejo majoritário aplicado pela quantificação não é garantia de que uma série de outros quesitos democráticos serão atendidos, especialmente: se a vontade da maioria preservará os direitos da minoria e se essa vontade da maioria não é um construto demagogicamente manipulado. Essa garantia dependerá da inafastabilidade da Ética à Democracia que, em linhas gerais, traduz-se no afastamento de qualquer tipo de violência física ou psíquica das interações sociais. 
ALVES, D. C.

Dito isto, Democracia é um certo conjunto de processos por meio de certas instituições. Sem instituições e processos democráticos, a simples expressão majoritária não torna algo necessariamente democrático.

Essas instituições do Estado, alongadas em assistencialistas, nas palavras de Adorno (1995), traduzem-se na

organização social em que vivemos continua sendo heterônoma, isto é, nenhuma pessoa pode existir na sociedade atual realmente conforme suas próprias determinações; enquanto isto ocorre, a sociedade forma as pessoas mediante inúmeros canais e instâncias mediadoras, de um modo tal que tudo absorvem e aceitam nos termos desta configuração heterônoma que se desviou de si mesma em sua consciência. É claro que isto chega até às instituições, até à discussão acerca da educação política e outras questões semelhantes (ADORNO, 1995, p.181-182).

Em um Estado democrático, a Liberdade é um dos valores fundamentais que baliza a ideia de governo da maioria, já que tem como uma de suas maiores expressões o pluralismo político manifestado pela convivência igualitária e justa independente se maioria ou minoria, cujo foco mira-se sempre na proteção dos direitos fundamentais a uma vida efetivamente ética.

Por liberdade, como apresentado, muitas são as suas definições e tipos, porém, independente dos seus vários sentidos, o que importa é que quem nomeia continua sendo o termo Liberdade, do qual se entende que o seu controle é o que a mitiga, isto é, não se trata de uma questão de querer a Liberdade, mas não deixar que ela seja controlada, perdida. E isso confere ao conceito de Liberdade uma vestimenta radical,

[...] a liberdade, que só raramente - em épocas de crise e revolução - se torna o alvo direto da ação política, é na verdade o motivo porque os homens convivem politicamente organizados. Sem ela, a vida política como tal seria destituída de significado. A raison d'être da política é a liberdade e seu domínio de experiência é a ação. [...] A liberdade que admitimos como instaurada em toda teoria política e que mesmo os que louvam a tirania precisam levar em conta é o próprio oposto da "liberdade interior", o espaço íntimo no qual os homens podem fugir 
ALVES, D. C.

à coerção externa e sentir-se livres. Esse sentir interior permanece sem manifestações externas e é, portanto, por definição, sem significação política. [...] A despeito da grande influência do conceito de uma liberdade interior e apolítica sobre a tradição do pensamento, parece seguro afirmar que o homem nada saberia da liberdade interior se não tivesse antes experimentado a condição de estar livre como uma realidade mundanamente tangível. Tomamos inicialmente consciência da liberdade ou do seu contrário em nosso relacionamento com outros, e não no relacionamento com nós mesmos (ARENDT, 2009, p. 192-194).

Não se perder no jogo do controle da Liberdade presume o direito à consciência crítica, avessa à domesticação e à cultura da imposição, como condição para se alcançar um novo patamar de raciocínio sobre si e o mundo. Quaisquer amarras que impeçam a formação de uma consciência crítica atentam contra a Liberdade, por sua vez, contra a consciência crítica, o que mina, em último, o próprio Estado democrático de direito, tendo em vista que,

ser crítico é ser capaz de enxergar o significado indireto ou implícito do produto intelectual, ou ser capaz de surpreender as verdadeiras "forças motrizes" que "movem" o produtor; é, em suma, ser apto a ver a estreita vinculação do pensamento com a situação existencial do pensador. Impossível, portanto, o exercício da crítica objetiva sem profundo conhecimento filosófico [...]. Precisamos, assim, provocar a polêmica, pois por meio dela é possível liquidar as moedas falsas que ainda circulam entre nós, com seu valor discutível (GUERREIRO RAMOS, 1957, p.30-31).

Nesse sentido, é dever do Estado que se diz democrático não apenas descrever constitucionalmente a Liberdade como um valor fundamental, mas munir a população de instituições e processos que possibilitem a transitividade de consciências ingênuas e mágicas para críticas, isto é, livres, pois é pela consciência crítica que se abre possibilidade para

a representação das coisas e dos fatos como se dão na existência empírica. Nas suas correlações causais e circunstanciais. A consciência ingênua (pelo contrário) se crê superior aos fatos, 
ALVES, D. C.

dominando-os de fora e, por isso, se julga livre para entendê-los conforme melhor lhe agradar. A consciência mágica, por outro lado, não chega a acreditar-se "superior aos fatos, dominando-os de fora, nem "se julga livre para entendê-los como melhor lhe agradar". Simplesmente os capta, emprestando-lhes um poder superior, que a domina de fora e a que tem, por isso mesmo, de submeter-se com docilidade. É próprio desta consciência o fatalismo, que leva ao cruzamento dos braços, à impossibilidade de fazer algo diante do poder dos fatos, sob os quais fica vencido o homem (FREIRE, 1967, p. 105).

Dentre as estratégias de Estado que permitem à nação se conhecer, condição basilar para o nascimento da consciência crítica de si e da realidade a que pertence, o Censo demográfico revela-se, desde o Brasil Imperial, como um instrumento para o despertar do Senso crítico, ou seja, para possibilitar um patamar de consciência crítica sobre a realidade demográfica e econômica do país, afastando, dessa forma, a consciência ingênua de si e do espaço que habita, pois, assim como é próprio do Censo permitir a apreensão da realidade geográfica do país, também “é próprio da consciência crítica a sua integração com a realidade, enquanto que da ingênua o próprio é sua superposição à realidade" (FREIRE, 1967, p. 105). Censo e Senso crítico são, portanto, indissociáveis para um Estado democrático que prioriza a Liberdade, especialmente, a Liberdade de consciência.

Nessa direção, Holt (2003) destaca que instrumentos estatísticos, o que inclui o Censo brasileiro, assumem imprescidibiidade para o bom fazer das políticas públicas ao

permitirem desenvolver e monitorar políticas públicas, alocar recursos e apoiar a administração pública na tomada de decisões financeiras. Eles também são úteis aos cidadãos para acompanharem o trabalho do próprio governo. Também são importantes do ponto de vista internacional, permitindo que governos nacionais monitorem o desempenho em relação a outros países, como aqueles com poder de compra; para garantirem que a competitividade econômica seja mantida ou melhorada; para monitorarem o desenvolvimento econômico e social em outros países e o resultado de alternativas 
ALVES, D. C.

econômicas ou políticas sociais adotadas [...] (HOLT, 2003, p. 4, tradução do autor).

Em se tratando do Brasil, que realiza a pesquisa censitária desde o ano de 1872, tendo a última ocorrido "no período de $1^{\text {o }}$ de agosto a 31 de outubro de 2010, quando os recenseadores visitaram pouco mais de 67,5 milhões de domicílios" (IBGE, 2010), pelo que, o quadro estatístico que se conhece hoje, a mais de uma década, pauta-se em estimativas, o que enfraquece a assertividade de políticas públicas atuais, cujas informações estatísticas "são imprescindíveis para a tomada de decisões de investimentos público e privado e contribuem para planejar adequadamente o uso sustentável dos recursos" (IBGE, 2010).

É importante destacar que, desde o seu início rudimentar, a pesquisa censitária passou por aperfeiçoamentos técnicos, os quais lhe dão, na conjuntura contemporânea marcada pela prodominância das $\mathrm{TDIC}^{2}$, um grau de precisão cirúrgica sobre a realidade do Brasil, oferecendo

uma visão completa e atual do País, através do desempenho de suas principais funções:

- Coordenação dos Sistemas de Informações Cartográficas e Estatísticas

- $\quad$ Produção de Informações Estatísticas

- Produção de Informações Geocientíficas

- Produção de Informações Censitárias

- $\quad$ Produção de Informações Ambientais

- Disseminação de Informações

- $\quad$ Gestão do Ensino Superior, Pesquisa e Extensão (IBGE, 2010).

Para além das supracitadas funções, o Censo Demográfico que, como já conceituado, se constitui como “a mais complexa operação estatística realizada por um país, sobretudo quando ele tem dimensões continentais como o Brasil, com 8.515.692,27 km², distribuídos em um território heterogêneo, muitas vezes de difícil acesso, composto por 27 Unidades da Federação" (IBGE, 2010), contempla, ainda, processos de Governança Institucional e de suporte: Gestão da Tecnologia da Informação e Comunicação, Gestão Administrativa, Gestão de Pessoas.

\footnotetext{
2 "Para alcançar os melhores padrões de qualidade no Censo 2010, o IBGE introduziu várias inovações gerenciais, metodológicas e tecnológicas, com destaque para a atualização da base territorial digital, a adoção do computador de mão equipado com GPS, para a coleta dos dados, e a introdução da internet como alternativa para preenchimento do questionário e a informatização dos cerca de 7.000 postos de coleta instalados pelo IBGE para gerenciar o Censo 2010 em todos os 5565 municípios brasileiros" (IBGE, 2010).
} 
Ao mesmo tempo, sabe-se da potencialidade geopolítica que o Censo exerce, dado que, apropriar-se da realidade geográfica de um país significa nutrir o sujeito do conhecimento das fragilidades e potencialidades de uma nação. E, como dizia Bacon (1988), filósofo empirista, oferecer informação é oferecer controle, pois essa oferta gera conhecimento, que é o poder em si mesmo. Por isso, tanto a oferta quanto a não oferta do Censo pelo Estado brasileiro, é uma questão de controle, é um ato de poder, haja vista que, considerando que "poder e conhecimento são sinônimos [...] o que importa não é aquela satisfação que, para os homens, se chama "verdade", mas a 'operation', o procedimento eficaz" (ADORNO; HORKHEIMER, 1985, p. 20).

Assim, ainda que se saiba que o Censo seja, em si, uma informação geradora de conhecimento, logo, instrumento de poder, o conflito com a Liberdade reside na discricionariedade do Estado que exerce o seu poder camuflado, quando o oferta no formato e no conteúdo determinado unilateralmente e, latente, quando cogita a privação do acesso do sujeito a esse conhecimento. Esse conflito tem origem, como mencionado, no que Adorno e Horkheimer (1985) chamam operation, a manifestação da manipulação procedimental da construção da consciência social.

Ante o exposto, apreende-se que a manipulação é uma estratégia antidemocrática que atenta sobre o direito da Liberdade do sujeito construir uma consciência livre. Esse tipo de estratégia é típico de uma geopolítica avessa à Democracia, já que enxerga a consciência do sujeito como "a qualidade humana última e, sem dúvida, a mais preciosa, pois o que é último é, ao mesmo tempo, o que há de melhor e de mais frágil. E, de fato, a consciência é extremamente frágil e, em sua fragilidade, pode enganar-se muitas vezes"' (MORIN, 2004, p. 126).

Nesse sentido, não surpreende que muitos serão os esforços para impossibilitar a sociedade da tomada de consciência. Negar a transparência da informação geográfica do Brasil, isto é, impedir que a população brasileira saiba da sua realidade demográfica e econômica, portanto, impossibilitar que a população tome consciência de si e do seu espaço, significa negar a própria Democracia. 
Negação que se traveste na dócil justificativa oficial de que sua causa foi provocada por fator externo e excepcional, quando se sabe que, na realidade, faz parte do operation, do modus operandi da tergiversante estratégia de atribuir a um elemento externo a impossibilidade de uma gestão transparente da informação geográfica, que deveria ter como pilar democrático o amplo acesso e divulgação do fazer político à sociedade.

Em sua, esconde-se a permissividade intencional em minar com o princípio da Liberdade de consciência tendo como argumento a atenuante externalização dessa escolha, uma vez que este será um motivo docilmente aceito por homens-objeto que se valem do mesmo argumento para justificarem o gosto pela submissão travestida na retórica vontade por Liberdade.

\section{Considerações finais}

Ancorado no argumento de indisponibilidade de recursos econômicos, o Estado brasileiro tem justificado cortes financeiros em áreas como Educação, Meio ambiente e Defesa. Com esse mesmo argumento, em 2021, comunicou à nação sobre a não realização do Censo Demográfico, o qual já estava em atraso no mencionado ano, por força de um decreto de emergência, devido ao momento pandêmico que assola a humanidade.

O seu adiamento já não foi decisão mais acertada, inclusive porque o Censo é essencial para se entender as dinâmicas de um Brasil que claudica com a pandemia, no entanto, cancelá-lo é pior ainda, traduz-se num ato, no mínimo, irracional, sobretudo porque o Censo trata de disponibilizar a informação, o que lhe caracteriza como uma atividade essencial.

A sua não realização já traz impactos negativos aos mais diversos setores da sociedade que são beneficiados pelos dados que são a matéria-prima para a elaboração de políticas públicas para áreas como: saúde, educação, planejamento, 
moradia, economia, ciência e tecnologia. Com o Censo obtêm-se as informações do território nacional, que se traduzem num retrato atual e histórico do país.

Contudo, abrir mão desse estudo decenal que, desde 1872, possibilita orientar ações do governo em relação às necessidades básicas da população, não se trata apenas de um poder de Estado avesso a uma gestão planejada, significa negligenciar preceitos constitucionais maiores que regem um Estado democrático de direito.

Em defesa desses preceitos se fez necessária a interferência do judiciário, que determinou a realização do Censo Demográfico para o ano de 2022 sob a explícita fundamentação de que o direito à informação é basilar para o Poder Público formular e implementar políticas públicas.

Em meio a essa contenda envolvendo o Censo, na cena social brasileira atual, pilares como Justiça, representada pelo seu mais alto símbolo, o STF, e Educação, corporificada pelas universidades públicas e seus sujeitos, têm sido alvos de ataques discursivos pelo próprio Estado que se diz democrático, parecendo haver uma intenção do esfacelamento das instituições que propiciam os processos democráticos em uma sociedade.

Esses ataques têm sido, constantemente, objeto de análise geopolítica, cuja constituição de um governo eleito pelos preceitos constitucionais democráticos parece operar no sentido de minar com a racionalidade prática da Democracia.

Em relação à produção do conhecimento científico, este, a todo momento, é desacreditado pelo Estado. A imposição judicial para a realização do Censo pelo Instituto Brasileiro de Geografia e Estatística (IBGE) torna visíveis os impactos causados pelos retrocessos no campo científico diante da supremacia de um governo que nega a ciência.

Em linhas gerais, a principal conclusão que aqui se chega, é que o Censo Demográfico não é apenas uma questão de quantificar e localizar espacialmente pessoas, mas de Senso Democrático. E ignorar a importância desse instrumento para a construção de uma consciência social cada vez mais livre é o mesmo que impedi-la 
do seu direito de Liberdade, sobretudo, numa contemporaneidade marcada por crises dos valores fundamentais de uma sociedade democrática.

Censo é, portanto, uma questão de Senso, porque ele emana poder, cuja apropriação do conhecimento do perfil sócio, econômico, cultural e demográfico de uma população, a depender da intencionalidade, pode resultar em manipulação da consciência alheia.

Sem o Censo, perdem a sociedade, a economia, a cultura, a ciência e, principalmente, a Democracia. Em suma, todo o Brasil sai prejudicado ao desconhecer o retrato da sua realidade, ainda que essa radiografia demográfica revele uma realidade de direito e não propriamente de fato.

\section{Referências}

ADORNO, Theodor W..; HORKHEIMER, Max. Dialética do Esclarecimento. Rio de Janeiro: Jorge Zahar, 1985.

ADORNO, Theodor W. Educação e Emancipação. Trad. de Wolfgang Leo Maar. In: Educação e Emancipação. Rio de Janeiro: Paz e Terra, 1995.

ARENDT, Hannah. Entre o passado e o futuro. 6. ed. São Paulo: Perspectiva, 2009.

BACON, Francis. Novum Organum. São Paulo: Nova Cultural, 1988 (Os

Pensadores).

BRASIL. Constituição da República Federativa do Brasil de 1988. Brasília, 1988.

Disponível em: http://www.planalto.gov.br/ccivil_03/constituicao/constituicao.htm. Acesso em: 01 jun. 2021.

BRASIL. Supremo Tribunal Federal. Inquérito 4.781, Distrito federal. Decisão. Ministro Alexandre de Moraes. Brasília, 2021. Disponível em: http://www.stf.jus.br/arquivo/cms/noticiaNoticiaStf/anexo/INQ4781FLAGRANTEDE LITODECISAO.pdf. Acesso em: 03 jun. 2021.

BRASIL. Supremo Tribunal Federal. Petição 8.645, Distrito federal. Decisão. Ministro Ricardo Lewandowski. Brasília, 2020. Disponível em: http://www.stf.jus.br/arquivo/cms/noticiaNoticiaStf/anexo/PET8645.pdf. Acesso em: 03 jun. 2021. 
ALVES, D. C.

BRASIL. Supremo Tribunal Federal. Petição 9.595, Distrito federal. Decisão. Ministra Cármen Lúcia. Brasília, 2021. Disponível em:

http://www.stf.jus.br/arquivo/cms/noticiaNoticiaStf/anexo/PET9595deciso.pdf. Acesso em: 03 jun. 2021.

BRASIL. Supremo Tribunal Federal. Tutela antecipada na ação cível originária 3.508, Distrito federal. Decisão. Ministro Marco Aurélio. Brasília, 2021. Disponível em: http://www.stf.jus.br/arquivo/cms/noticiaNoticiaStf/anexo/ACO3508.pdf. Acesso em: 03 jun. 2021.

BRASIL. Supremo Tribunal Federal. Medida cautelar em mandado de segurança 37.760, Distrito federal. Decisão. Ministro Roberto Barroso. Brasília, 2021. Disponível em:

http://www.stf.jus.br/arquivo/cms/noticiaNoticiaStf/anexo/MS37760decisaoMRB.pdf. Acesso em: 03 jun. 2021.

BRASIL. Lei no 8.184, de 10 de maio de 1991. Dispõe sobre a periodicidade dos Censos Demográficos e dos Censos Econômicos e dá outras providências. Diário Oficial da União, 13 de maio de 1991. Brasília, 1991. Disponível em: http://www.planalto.gov.br/ccivil_03/leis/18184.htm. Acesso em: 03 jun. 2021.

BRASIL. Lei $\mathrm{n}^{\mathrm{o}} 1.579$, de 18 de março de 1952. Dispõe sobre as Comissões Parlamentares de Inquérito. Diário Oficial da União, 21 de março de 1952. Brasília, 1952. Disponível em: http://www.planalto.gov.br/ccivil_03/leis/11579.htm. Acesso em: 03 jun. 2021.

BRASIL. Congresso Nacional. Requerimento de Instituição de CPMI no 11, de 2019. (Do Senhor Alexandre Leite e Outros). 2019. Disponível em:

https://legis.senado.leg.br/sdleg-

getter/documento?dm=7974346\&ts=1612894020662\&disposition=inline. Acesso em: 03 jun. 2021.

BRENNAN, Jason. (2016). Contra a Democracia. $1^{\underline{a}}$ edição, tradução de Elisabete Lucas, Gradiva, Lisboa, 2017.

CORTINA, Adela. O fazer ético. São Paulo: Moderna, 2003.

FREIRE, Paulo. Educação como prática de liberdade. 1 ed. Rio de janeiro: Paz e Terra, 1967.

GUERREIRO RAMOS, Alberto. Introdução à crítica à sociologia brasileira. Rio de Janeiro: Editorial Andes, 1957. 
HAMILTON, Alexander; MADISON, James; JAY, John. O Federalista. São Paulo: Abril Cultural, 1985.

HOLT, David. Methodological Issues in the Development and Use of Statistical Indicators for International Comparisons. Survey Methodology. Vol. 29, No. 1, Statistics Canada, Catalogue No. 12-001, 2003. Disponvel em: https://www150.statcan.gc.ca/n1/en/pub/12-001-x/2003001/article/6600eng.pdf?st=q6ILVzK8. Acesso em: 23 dez. 2021.

IBGE - Instituto Brasileiro de Geografia e Estatítica. Censo demográfico 2010. Disponível em: https://dados.gov.br/organization/about/instituto-brasileiro-degeografia-e-estatistica-ibge. Acesso em 23 dez. 2021.

KANT, Immanuel. Resposta à pergunta: o que é esclarecimento? Petrópolis: Vozes, 1985.

LA BOÉTIE, Étienne de. Discours de la servitude volontaire. Chronologie, introduction, bibliographie et notes par. Paris: Payot, 1976.

MIGNOLO, Walter D. Desobediência epistêmica: opção descolonial e o significado de identidade em política. Trad. Ângela Lopes Norte. Cadernos de Letras da UFF Dossiê: Literatura, língua e identidade, nº 34, p. 287-324, 2008.

MORIN, Edgard. A cabeça bem-feita: repensar a reforma, reformar o pensamento. 9a Ed. Rio de Janeiro: Bertrand Brasil, 2004.

RIBEIRO, Djanira. O que é lugar de fala? Belo Horizonte: Letramento; Justificando, 2017.

SARTRE, Jean Paul. O ser e o nada - ensaio de ontologia fenomenológica.

Tradução: Paulo Perdigão. 6 ed. Rio de Janeiro: Vozes, 1998.

SARTRE, Jean Paul. L'Existentialisme est un Humanisme. Tradutora: Rita Correia Guedes. Les Éditions Nagel, Paris, 1970.

SODRÉ, Muniz. O monopólio da fala: função e linguagem da televisão no Brasil. Petrópolis: Vozes, 1981. 